\title{
Development and validation of the Oral Health Behavior Questionnaire for Adolescents based on the Health Belief Model (OHBQAHBM)
}

\section{Bilu Xiang}

University of Hong Kong

Hai Ming Wong ( $\nabla$ wonghmg@hku.hk)

The University of Hong Kong https://orcid.org/0000-0003-3411-6442

\section{Wangnan Cao}

University of Hong Kong

Antonio P. Perfecto

University of Hong Kong

Colman P.J. McGrath

University of Hong Kong

Research article

Keywords: Questionnaires, Adolescents, Oral health-related behavior, Validation, Psychological factor

Posted Date: March 2nd, 2020

DOI: https://doi.org/10.21203/rs.3.rs-15693/v1

License: (c) (1) This work is licensed under a Creative Commons Attribution 4.0 International License. Read Full License

Version of Record: A version of this preprint was published at BMC Public Health on May 15th, 2020. See the published version at https:// doi.org/10.1186/s12889-020-08851-x. 


\section{Abstract}

Background Oral health belief is a prerequisite of changing oral health behaviors especially during adolescence. However, there is a paucity of well-established questionnaire for use among adolescents. This study aimed to develop and validate an instrument to evaluate adolescents' beliefs about oral health behaviors using health belief model.

Methods A preliminary 43-item questionnaire was developed by an expert panel. Then the questionnaire was finalized by decreasing the number of items to 35 by analyzing the results from face validity and factor analysis from 421 Hong Kong secondary school students. The content validity were evaluated by a panel of 2 behavioral scientists, 2 dentists, 2 schoolteachers and 10 adolescents. The construct validity of the questionnaire was assessed by performing exploratory factor analysis (EFA) and confirmatory factor analysis (CFA). The Cronbach's alpha coefficient, item-total correlation and intraclass coefficient were used to test its reliability. In addition, to confirm its applicability, multiple regression analysis and path analysis were used to evaluate the possibility of HBM as predictors for oral health behaviors and oral hygiene status.

Results The initial analysis extracted six factors that jointly accounted for $62.47 \%$ of the variance observed. Based on CFA, the final version of the questionnaire consisted of 35 items and the data of the final version fitted the model well. The Cronbach's alpha coefficient for the subscale $(>0.7)$, item-total correlations (0.47-0.91) and the intraclass coefficient (0.82-0.91) were all above acceptable thresholds. The results of multiple regression analysis and path analysis confirmed its ability to predict oral health behaviors and status.

Conclusions The present findings indicate satisfactory validity, reliability and applicability of the proposed Oral Health Behavior Questionnaire for Adolescents based on the Health Belief Model (OHBQAHBM) for measuring oral health beliefs of adolescents. This questionnaire can be used as an instrument to measure oral health beliefs and predict oral health behavior and oral hygiene status of adolescents.

\section{Background}

Oral health is an integral part of general health, which influences various aspects of life, such as chewing, speaking, appearance and socializing [1, 2]. Dental complications can result in the absence from school and poorer academic performance [3]. Oral diseases are major public health problems, which rank as the fourth most expensive diseases in developed countries [2]. In some countries, the expenditure on dental caries of children alone exceeds the total budget for children's oral health care [4]. Some preventive measures, such as water fluoridation, help to reduce the occurrence of caries, but inadvertently increase the prevalence and severity of fluorosis [5]. Adolescence is a formative period for young people to develop their adult lifestyles, including oral health behaviors [6]. However, inadequate attention and guidance have 
been given for dental health care [7], especially in Hong Kong. For instance, the use of dental floss and annual dental visitations among Hong Kong adolescents remain relatively unimportant [8].

Multiple theories have long been applied to explain the psychological determinants of behavior and health promotion [9]. The health belief model (HBM), consisting of six main concepts: perceived susceptibility, perceived benefits, perceived severity, perceived barriers, cues to action and self-efficacy, is one of the most widespread behavioral science models $[10,11]$. Based on the HBM, oral health belief has been shown to be a prerequisite of changing oral health behaviors [12]. Several studies have confirmed the applicability and effectiveness of HBM in predicting oral health behaviors [11, 13]. No previous standard instrument has been validated to assess adolescents' beliefs towards oral health behaviors. In order to provide a more targeted oral health service plan specifically designed for adolescents, it is important to collect information about their attitudes and beliefs towards oral health behaviors.

Therefore, this study aimed at developing and validating a specific instrument, the Oral Health Behavior Questionnaire for Adolescents based on the Health Belief Model (OHBQAHBM), which measures factors affecting oral health behaviors of adolescents based on the HBM. In addition, we tried to describe the relationship among oral health beliefs, oral health behaviors and oral hygiene status.

\section{Methods}

\section{Ethical considerations}

The study was approved by the HKU/HA HKW Institutional Review Board (IRB HKU: UW17-348). Written consents from the parents were obtained and confidentiality of their privacy was assured. The rights of participants to withdraw at any time were guaranteed.

Phase I: Development and pilot test of the questionnaire

\section{Literature searching and drafting}

Prior to the study, a literature search was performed between April and June 2018 to identify instruments that adopted HBM components within an oral health context. The Cochrane Library, PubMed, and Google Scholar databases were searched using keywords: oral health, health belief model/ HBM, adolescent, child, schoolchildren, validation and development of instruments. We did not identify any validated oral health-related instruments based on HBM specifically designed for adolescents. Three researchers (one with extensive experience in the development of psychometric questionnaires, one with professional knowledge in adolescence health behaviors, and the other Specialist in Pediatric Dentistry) drafted the questionnaire after referring to the questionnaires utilized in similar contexts [14-16]. The drafted questionnaire containing 43 items was sent to a linguistics expert for verification of clarity, conciseness and grammar.

Face and content validity 
A panel of 2 behavioral scientists, 2 dentists and 2 schoolteachers were invited to investigate the relevance and conceptual scope of the items in relation to HBM. After discussion, all panel members agreed with some minor modifications and to delete one item from the questionnaire. The revised questionnaire was pilot-tested with a convenience sample of 10 adolescents (12-17y) to ensure the clarity of the questionnaire. The time required to complete the questionnaires was approximately 15-20 minutes for each individual. These adolescents were encouraged to ask any question and make comments to any part of the questionnaire. All comments and suggestions were considered to omit potential misunderstandings. The initial version contained 42 items in six subscales which include: Perceived Susceptibility (SUS 1-2), Perceived Benefits (BEN 3-10), Perceived Barriers (BAR 11-19), Cues to Action (CUE 20-23), Perceived Severity (SEV 24-32), Self-efficacy (EFF 33-42). A five-point Likert format was adopted in the options of answers. The items of SUS, BEN, BAR and CUE have the following response options: strongly disagree (scores 1 point), disagree (scores 2 points), neutral (scores 3 points), agree (scores 4 points) and strongly agree (scores 5 points). The items of SEV have response choices: not serious (scores 1 point), a little serious (scores 2 points), partially serious (scores 3 points), serious (scores 4 points) and very serious (scores 5 points). The items of EFF include five choices of answers: not confident (scores 1 point), a bit confident (scores 2 points), fairly confident (scores 3 points), quite confident (scores 4 points) and very confident (scores 5 points). The average score of each subscale was calculated to represent the individual's belief towards that specific domain. For each subscale, higher scores indicate stronger feelings towards each domain.

Phase II: Item reduction and questionnaire testing

\section{Questionnaire structure}

The version-1 of the questionnaire consisted of the following three sections. The first part contained the demographic information (age and gender); the second part included the 42-item structured questionnaire about the constructs of HBM; the third part consisted of three questions concerning oral health behaviors. In the third part, respondents were asked to report the frequency of tooth brushing (1. Less than twice a day; 2. Twice or more a day), flossing frequency (1. Less than once a week or never; 2 . Once or more a week) and dental visits (1. No regular dental visit; 2. Have an annual dental visit). Data were collected from July to September 2018. In order to perform test-retest reliability analysis, 40 adolescents from the sample $(n=421)$ were randomly selected to complete the questionnaire twice within a two-week interval.

\section{Sampling}

The version- 1 of the questionnaire was administered to adolescents in Hong Kong. The sample size was determined by referencing the requirements of explanatory factor analysis (EFA). As a general rule of thumb, a subject-to-item ratio of 1:10 was adopted [17]. At last, the sample size was calculated as 420 . Each secondary school in Hong Kong was assigned a number (1 to 113) and three schools were randomly selected from a random numbers table. Afterward, all S2 students of these three schools were assigned a number and 470 students were invited to participate by selecting from the random numbers 
table, with an expected $90 \%$ response rate. Participants undergoing orthodontic treatments were excluded. Finally, 421 adolescents were eligible and agreed to participate in the study.

\section{Clinical measurements}

The visual plaque index (VPI) score [18] was used to evaluate plaque accommodation at buccal surfaces of teeth. An index for the entire mouth is determined as dividing the total score by the number of surfaces examined. Two trained and calibrated dentists conducted the dental examination in schools. Calibration was executed on a separate sample of adolescents ( $n=27,11$ boys and 16 girls) prior to the study. The weighted kappa coefficient value for inter-examiner reliability was 0.87 . Then the dentists rated the same adolescents for VPI one hour later to determine intra-examiner reliability. The weighted kappa coefficient value was 0.94 for examiner 1 and 0.88 for examiner 2. Both examiners showed good reliability.

\section{Construct validity for item reduction}

SPSS 25.0 and AMOS 22.0 were utilized to analyze data. Construct validity was examined using EFA and confirmatory factor analysis (CFA). The principal component analysis with a varimax rotation was applied to extract factors. Kaiser-Mayer-Olkin $(\mathrm{KMO})>0.6$ and Bartlett's test for sphericity $(P<0.05)$ were considered as sampling adequacy. Parallel analysis was conducted for factor extraction [17]. The extracted factors were rotated orthogonally using the varimax procedure. The acceptable level of factor loading was set at 0.3 and above $[19,20]$. CFA was performed to evaluate the coherence between the data and the structure model. The model fit was evaluated using multiple fit indices, including the chi-square statistics ( $\mathrm{X} 2)$; normed chi-square ( $\mathrm{X} 2 / \mathrm{df})$; comparative fit index (CFI); Tucker-Lewis index (TLI); and root mean square error of approximation (RMSEA). CFI $>0.90, \mathrm{TLI}>0.90$, RMSEA and SRMR $<0.06$ indicated a good fit (SRMR $<0.08$ acceptable) $[21,22]$.

Phase III: Practicability of the questionnaire

\section{Reliability and stability}

The reliability of the final-version questionnaire was evaluated using item-total subscale correlations and Cronbach's alpha coefficients. A correlation of $<0.30$ between an item and the total subscale score was considered poorly functioned [20]. A value of 0.70 or above of Cronbach's alpha was considered evidence of internal consistency [23]. Stability was measured by performing test-retest reliability analysis via intraclass correlation coefficients (ICC). Values of ICC between 0.75 and 0.90 , and greater than 0.90 indicate good and excellent stability, respectively [24].

\section{Criterion validity for predicting oral health behaviors}

To explore the criterion-oriented validity of the final-version questionnaire, the association between desirable oral health behaviors (brushing twice or more a day, floss weekly or more, and regular dental visit) and HBM components including perceived susceptibility, perceived benefits, perceived barriers, 
perceived severity, cues to action and self-efficacy was evaluated by performing multiple logistic regression analysis.

\section{Structure equation modeling for predicting oral hygiene status}

Path analysis was utilized to assess the causal relationship between HBM beliefs, behaviors and oral hygiene status in AMOS 22.0. Based on the suggestion of previous investigations, perceived barriers might play the most important role in predicting behaviors in $\operatorname{HBM}[25,26]$. It was hypothesized in our model that perceived benefits, perceived severity, perceived susceptibility, self-efficacy and cues to action might influence behaviors through barriers. And all the beliefs would have a direct effect on oral health behaviors, which in turn would influence the oral hygiene status of adolescents (Fig 1a). Tooth brushing, flossing habits and dental visit patterns were converted to dummy variables ( $1=$ undesirable behaviors, 2 = desirable behaviors: brushing twice or more a day, flossing once a week or more, have an annual dental visit). Other variables in the model were used as continuous variables. Direct and indirect effects on VPI were estimated using bootstrap with bias-corrected $95 \%$ confidence intervals. The degree of correspondence between the conceptual model and actual data was evaluated using a good-of-fit test. The cut-off criteria to consider the model a good fit to the data included CFI >0.90, TLI >0.90, RMSEA and a standardized root mean square residual $($ SRMR $)<0.06$ [22].

\section{Results}

Phase II: Item reduction and questionnaire testing

\section{EFA Results}

In total, 421 secondary school students were entered into the study. The KMO value was 0.88 and Bartlett's test was $₫ 0.001$, which was adequate for EFA. Table 1 shows that six factors were extracted by using rotated factor analysis. The six factors jointly accounted for $62.49 \%$ variance observed. Factor 1 accounted for $24.79 \%$ of the variance, representing all 10 items of Self-efficacy scale. Factor 2 accounted for $11.91 \%$ of the variance and represented all items of Perceived benefits scale. The items of Perceived severity subscale were loaded together as factor 3 and accounted for $9.27 \%$ of the variance. Factor 4 accounted for $7.33 \%$ of the variance and represented items regarding the potential barriers. Factor 5 accounted for $5.21 \%$ of the variance and represented the cues to take action. Factor 6 accounted for $3.98 \%$ of the variance and represented the remaining two items regarding susceptibility (Table 1).

\section{CFA results}

CFA was used to test whether the pattern of relationships among the items could be explained by the sixfactor model extracted by EFA. At first, the measurement model did not fit the data. Overall, the loading factors of 7 items (BEN4, BAR12, BAR13, BAR14, CUE23, SEV31 and SEV32) were冈0.5 and were omitted from the final version. In addition, some correlations between the variables' errors were added to the model based on the modification indices. After the modification, the fit indices for the final 35-item model 
were $\chi^{2}=1415.32, \mathrm{df}=543, \mathrm{P}<0.001, \mathrm{CFI}=0.92, \mathrm{TLI}=0.91, \mathrm{RMSEA}=0.062(90 \% \mathrm{Cl} 0.058$ to 0.066$)$, indicating an acceptable fit to the data (Figure 2).

Phase III: Practicability of the questionnaire

The mean age of participants was $13.2(S D=0.5)$ years old and $50.1 \%$ of them were girls. Most of the adolescents brushed twice or more a day (80.8\%), had dental floss less than once a week (77.0\%) and did not have a regular dental visit plan $(65.8 \%)$. The mean subscale scores of the final-version questionnaire were $2.6 \pm 0.9$ for perceived susceptibility, $4.0 \pm 0.6$ for perceived benefits, $2.1 \pm 0.7$ for perceived barriers, $2.1 \pm 0.9$ for cues to action, $3.8 \pm 0.8$ for perceived severity, and $3.6 \pm 1.0$ for self-efficacy. The mean VPI score was 2.3 \pm 0.6 (Appendix Table 1).

\section{Reliability and stability}

After item reduction, we tested the reliability and stability of the final 35-item instruments. Score means, standard deviations, item-total correlations and Cronbach's alpha if item deleted for each question were listed in Table 2. Each items' item-total correlations were above 0.30 and Cronbach's alpha coefficient of the six subscales ranged from $0.81-0.97$ (Table 2). The intraclass coefficients ranged from 0.82 to 0.91 , demonstrating a good stability (Table 3 ).

\section{Criterion validity for predicting oral health behaviors}

The criterion validity was determined by evaluating the association between desirable oral health behaviors and HBM components. The logistic regression analysis was performed respectively for each dependent outcome variables (brushing, flossing and dental visit behavior). The independent variables, including perceived susceptibility, perceived barriers, perceived benefits, cues to action, perceived severity and self-efficacy, were entered into the model. The results are shown in Table 3. The outliers were excluded based on Cook's distances and standardized residuals. For predicting brushing behaviors, 412 cases were entered into the model and the full model was statistically reliable $\left(\chi^{2}=42.2, d f=6, p<0.001\right)$. This model explained $9.7 \%$ to $16 \%$ of the variance. The results showed that self-efficacy had a positive effect on brushing twice or more a day $(\mathrm{OR}=2.36,95 \% \mathrm{Cl}=1.70-3.28, \mathrm{p}<0.001)$. In addition, 418 adolescents were entered in the analysis to predict flossing behaviors $\left(x^{2}=30.0, d f=6, p<0.001\right)$. This model explained $6.9 \%-10.6 \%$ of the variance for weekly flossing. Perceived susceptibility (OR $=0.74,95 \%$ $\mathrm{Cl}=0.56-0.98, \mathrm{p}=0.04)$ and perceived barriers $(\mathrm{OR}=0.42,95 \% \mathrm{Cl}=0.26-0.68, \mathrm{p}<0.001)$ had a preventive effect on flossing habit. On the other hand, cues to action (OR=1.36, 95\% $\mathrm{Cl}=1.05-1.77, \mathrm{p}=0.02)$ increased the chance of performing a weekly flossing habit. Finally, 419 individuals were included in the full model to predict regular dental visit plans (Cox \& Snell $R^{2}=0.070$, Nagelkerke $R^{2}=0.098, \chi^{2}=30.6, d f=6$, $\mathrm{p}<0.001)$. Perceived barriers had a preventive effect on having dental visit plans $(\mathrm{OR}=0.33,95 \% \mathrm{Cl}=0.22$ $0.51, p<0.001)$. To conclude, the components of HBM was statistically associated with oral health behaviors, suggesting criterion-oriented validity. In addition, HBM variables might function as predictors for oral health behaviors. 
Based on the conceptual model, we developed an initial model involving all the variables that directly or indirectly affected VPI score which fit with the hypothesized model (TLI=0.960; CFI=0.993; RMSEA=0.027; $\left.S R M R=0.020 ; \chi^{2}=6.510 ; d f=5 ; p=0.260\right)$. After deleting some insignificant paths, the final model was developed (Figure 1b) and the goodness of model fit improved (TLI=1.042; CFI=1.000; RMSEA<0.001; $\left.S R M R=0.025 ; \chi^{2}=15.769 ; d f=23 ; p=0.865\right)$. Figure $1 b$ demonstrated that self-efficacy had a direct effect on VPI score ( $\beta=-0.105, p=0.015$, Appendix Table 2$)$. In addition, perceived susceptibility, perceived benefits, perceived severity, self-efficacy and perceived barriers all had significant indirect effects on VPI score $(p<0.05)$.

\section{Discussion}

The present study developed and validated an instrument for assessing factors related to oral health contexts for adolescents based on the HBM. To our knowledge, OHBQAHBM is the first validated HBMbased questionnaire for adolescents' oral health. The HBM was first developed in the 1950s and has been applied to a wide range of health behavior promotions [27]. This model emphasized two aspects of the individual's belief of health behaviors: threat perception and behavioral evaluation [28]. For health problem prevention, the individual should first feel personally susceptible to particular health issues (perceive susceptibility), be able to anticipate the potential severity of the illness (perceived severity), believe in the benefits of performing recommended health behaviors (perceived benefits) and be able to overcome the costs of enacting that particular behavior (perceived barriers) [27]. In addition, cues to action can activate health behaviors when self-efficacy is established [28, 29]. Fatemeh et al. found that HBM was able to predict oral health behaviors and the reduction of perceived barriers could help promote oral health behaviors [11]. With an increase in an individual's positive perceptions of HBM components, correct brushing and flossing practices were encouraged [30,31]. Furthermore, one study reported a correlation between the increasing perceived severity and a decrease of DMFT [30]. Therefore, the establishment of healthy oral behaviors in adolescence was essential because growth and development were highly influenced by the effects of oral diseases [32,33]. Dramatic improvement in adolescent oral health behaviors was optimized when changes in health beliefs occur; therefore developing a standard instrument to assess the beliefs of oral health behaviors for this specific age group was targeted.

In the present study, the construct validity was assessed to test the degree of data fit with the model by performing EFA and CFA. After deleting seven items, CFA indicated acceptable fit indices of the remaining 35 items for the six-domain constructual model. Then, the reliability and practicability of the final 35-item questionnaire were tested. The internal consistency reliability was strong for the overall scale as well as each subscale. The test-retest reliability and item-total correlation analysis were also assured, which further confirmed the practicability of the questionnaire.

Previous research has identified self-efficacy and perceived barriers as a predictor of toothbrushing and flossing behaviors [34,35]. Similarly, in our study, perceived barriers could serve as a predictor for flossing 
and dental visit patterns while self-efficacy predicted toothbrushing behavior. Moreover, perceived susceptibility and cues to action were significant factors for predicting flossing habit. It is interesting that there was no direct relationship between perceived severity/benefits and oral health behaviors, which is consistent with the previous study [35]. This result is contrary to the logic that one must feel threatened (perceived severity) and believe that the outcome of behavior change is favorable (perceived benefits) before one intends to change one's behavior. The possible explanation was that these two components influenced behavior change in a more complex way. For example, one study found that perceived severity was more effective when self-efficacy was higher [36]. On the other hand, perceived benefits might play a role at a later stage when self-efficacy and severity were high [25]. On the whole, the HBM variables couldn't perfectly explain the variance of oral health-related behaviors. It might be due to the reason that the oral health behaviors recorded in our study were not exhaustive. Detailed information such as the technique of brushing and types of toothbrush may need to be collected in future studies.

To further explore the direct and indirect effect of HBM components on oral hygiene status, the path analysis was conducted. Previous research has tried to refine the model and the perceived barriers have been identified as a strong predictor for behaviors [37]. In fact, the dominant effect of perceived barriers on oral health status has also been confirmed [30]. The unique status of perceived barriers might be derived from the fact that it focused on the current problems for adopting a behavior, rather than a perception of possible future outcomes. Accordingly, the other five components had a significant direct effect on perceived barriers based on our results. Self-efficacy was the only factor identified in our model that had a direct effect on VPI score. This result was in accordance with the findings of Mizutani that selfefficacy had a direct effect on oral health [38]. It indicated that the decision to perform oral health practices was influenced by the confidence of doing it successfully. In the present study, except for cues to action, other factors were all found to have a significant indirect effect on oral hygiene. The possible reason might be that cues to action remained undeveloped in the whole framework of HBM and this study only evaluated the external cues. However, a meta-analysis pointed out that the size of the effects for HBM components varied if the targeted behavior differed [37]. In addition, their effects on behavior might also be moderated by each other [39]. Therefore, the theoretical path of HBM's effect on behaviors and health outcomes is not understood by now due to its complexity and interactions within HBM components.

Apart from the unexhausted recording of oral health behaviors, there are other limitations in this study. First, we did not collect data about the caries status of Hong Kong adolescents, because the caries prevalence of Hong Kong adolescents remained low based on the oral health survey in 2013 [40] and VPI can reflect the effectiveness of oral health behaviors in a more direct way. Second, our student sample represents a specific, narrow population in Hong Kong. Hence, this instrument should be tested in different populations to assess its generalizability. Third, it is not a longitudinal study; therefore, the model hypothesized from this study was not definitive.

\section{Conclusion}


Overall, our findings strongly suggest that the final version of the 35-item scale based on the HBM is a valid and reliable instrument for measuring factors influencing oral health behaviors for adolescents. HBM variables can be used as predictors for oral health behaviors and oral health status. Additional research is recommended to evaluate the practicability, generalizability and applicability of this instrument to other populations.

\section{Abbreviations}

$\mathrm{HBM}$, health belief model; VPI, visual plaque index; KMO, Kaiser-Mayer-Olkin; CFI, comparative fit index; TLI, Tucker-Lewis index; RMSEA, root mean square error of approximation; ICC, correlation coefficients; SRMR, standardized root mean square residual; EFA, exploratory factor analysis; CFA, Confirmatory factor analysis.

\section{Declarations}

Ethical approval

The study was approved by the HKU/HA HKW Institutional Review Board (IRB HKU: UW17-348).

Consent for publication

Not applicable

Availability of data and material

The datasets used and/or analyzed during the current study are available from the corresponding author on reasonable request.

Competing interest

The authors declare that they have no competing interests.

Funding

This research did not receive any funding from granting agencies in the public, commercial, or not-forprofit sectors.

Authors' contribution

$B X, W C$ and HMW drafted the questionnaire. HMW and CPJM refined the questionnaire. BX and APP collected the initial data. BX performed data entry, data analysis and drafted the initial manuscript. HMW designed and coordinated the study, and refined the manuscript. All authors read and approved the final manuscript. 
Acknowledgment

The author would like to thank all the participating adolescents.

\section{References}

1 Sadamori S, Hayashi S, Hamada T. The relationships between oral status, physical and mental health, nutritional status and diet type in elderly Japanese women with dementia. Gerodontology. 2008;25(4):205-9.

2 Petersen PE. The World Oral Health Report 2003: continuous improvement of oral health in the 21st century-the approach of the WHO Global Oral Health Programme. Community Dent Oral Epidemiol. 2003;31:3-24.

3 Dye B, Li X, Thornton-Evans G. Oral health disparities as determined by selected Healthy People 2020 oral health objectives for the United States, 2009-2010. NCHS Data Brief. 2012; (104):1-8.

4 Kathmandu RY. The burden of restorative dental treatment for children in Third World countries. Int Dent J. 2002;52(1):1-9.

5 Wong HM, McGrath C, King NM. Diffuse opacities in 12-year-old Hong Kong children-four crosssectional surveys. Community Dent Oral Epidemiol. 2014;42(1):61-9.

6 Al Johara A. Factors affecting utilization of dental health services and satisfaction among adolescent females in Riyadh City. Saudi Dent J. 2010;22(1):19-25.

7 McGrath C, Sham ASK, Ho DKL, Wong JHL. The impact of dental neglect on oral health: a population based study in Hong Kong. Int Dent J. 2007;57(1):3-8.

8 Mak KK, Day JR. Dental health behaviours among early adolescents in Hong Kong. Int J Dent Hyg. $2011 ; 9(2): 122-6$.

9 Painter JE, Borba CP, Hynes M, Mays D, Glanz K. The use of theory in health behavior research from 2000 to 2005: a systematic review. Ann Behav Med. 2008;35(3):358-62.

10 Rahmati-Najarkolaei F, Tavafian SS, Fesharaki MG, Jafari MR. Factors predicting nutrition and physical activity behaviors due to cardiovascular disease in tehran university students: application of health belief model. Iran Red Crescent Med J. 2015;17(3).

11 Rahmati-Najarkolaei F, Rahnama P, Fesharaki MG, Behnood V. Predictors of oral health behaviors in female students: an application of the health belief model. Iran Red Crescent Med J. 2016;18(11).

12 Hollister MC, Anema MG. Health behavior models and oral health: a review. J Dent Hyg. 2004;78(3):6-. 
13 Bahramian H, Mohebbi SZ, Khami MR, Sighaldeh SS. A Health Belief Model-Based Instrument for Assessing Factors Affecting Oral Health Behavior During Pregnancy. Iran Red Crescent Med J. 2017;19(8).

14 Nakazono T, Davidson P, Andersen R. Oral health beliefs in diverse populations. Adv Dent Res. 1997;11(2):235-43.

15 Lee CY, Ting CC, Wu JH, Lee KT, Chen HS, Chang YY. Dental visiting behaviours among primary schoolchildren: Application of the health belief model. Int J Dent Hyg. 2018;16(2):e88-e95.

16 Aleksejūnienè J, Brukienè V, Džiaugyte L, Pečiulienè V, Bendinskaitè R. A theory-guided school-based intervention in order to improve adolescents' oral self-care: a cluster randomized trial. Int J Paediatr Dent. 2016;26(2):100-9.

17 McCoach DB, Gable RK, Madura JP. Instrument development in the affective domain. New York, NY: Springer. 2013.

18 Turesky S, Gilmore ND, Glickman I. Reduced plaque formation by the chloromethyl analogue of victamine C. J Periodontol. 1970;41(1):41-3.

19 Munro BH. Statistical methods for health care research. The United States: lippincott williams \& wilkins; 2005.

20 Guvenc G, Akyuz A, Açikel CH. Health belief model scale for cervical cancer and Pap smear test: psychometric testing. J Adv Nurs. 2011;67(2):428-37.

21 Joseph FH. William CB. Barry JB. Rolph EA. Multivariate data analysis. Seventh Edition. The United States: Pearson Education Limited; 2014.

$22 \mathrm{Hu}$ Lt, Bentler PM. Cutoff criteria for fit indexes in covariance structure analysis: Conventional criteria versus new alternatives. Struct Equ Modeling. 1999;6(1):1-55.

23 Brink PJ, Wood MJ. Advanced design in nursing research: Sage; 1998.

24 Koo TK, Li MY. A guideline of selecting and reporting intraclass correlation coefficients for reliability research. J Chiropr Med. 2016;15(2):155-63.

25 Jones CL, Jensen JD, Scherr CL, Brown NR, Christy K, Weaver J. The health belief model as an explanatory framework in communication research: Exploring parallel, serial, and moderated mediation. Health Commun. 2015;30(6):566-76.

26 Sharma M. Theoretical foundations of health education and health promotion. England: Jones \& Bartlett Publishers; 2016. 
27 Rosenstock IM. Historical origins of the health belief model. Health education monographs. 1974;2(4):328-35.

28 Mark C, Paul N. Predicting and Changing Health Behaviour: Research and Practice with Social Cognition Models. United Kingdom: Open University Press; 2015.

29 Bandura A, Freeman W, Lightsey R. Self-efficacy: The exercise of control. Washington: Worth Publishers; 1997.

30 Solhi M, Zadeh DS, Seraj B, Zadeh SF. The application of the health belief model in oral health education. Iran J Public Health. 2010;39(4):114.

31 Hosseini M, Bekry G, Mozaffari HR, Sadeghi R, Yousefifard M, Rostambeigi M, et al. Effect of Educational Intervention on Oral Health Behaviour based on Health Belief Model in Female Secondary School Students of Paveh in 2011. Res Med Sci J. 2014;2(3):2-9.

32 Goldfeld S, Kilpatrick N. Oral health: An important determinant of the health of children. J Paediatr Child Health. 2007;43(3):99-100.

33 Li L-W, Wong HM, Sun L, Wen YF, McGrath CP. Anthropometric measurements and periodontal diseases in children and adolescents: a systematic review and meta-analysis. Adv Nutr. 2015;6(6):828-41.

34 Kasmaei P, Shokravi FA, Hidarnia A, Hajizadeh E, Atrkar-Roushan Z, Shirazi KK, et al. Brushing behavior among young adolescents: does perceived severity matter. BMC Public Health. 2014;14(1):8.

35 Buglar ME, White KM, Robinson NG. The role of self-efficacy in dental patients' brushing and flossing: testing an extended Health Belief Model. Patient Educ Couns. 2010;78(2):269-72.

36 Witte K. Putting the fear back into fear appeals: The extended parallel process model. Communications Monographs. 1992;59(4):329-49.

37 Carpenter CJ. A meta-analysis of the effectiveness of health belief model variables in predicting behavior. Health Commun. 2010;25(8):661-9.

38 Mizutani S, Ekuni D, Furuta M, Tomofuji T, Irie K, Azuma T, et al. Effects of self-efficacy on oral health behaviours and gingival health in university students aged 18-or 19-years-old. J Clin Periodontol. 2012;39(9):844-9.

39 Strecher VJ, Champion VL, Rosenstock IM. The health belief model and health behavior. New York: Plenum Press; 1997.

40 Department of Health: Oral health survey 2001. Hong Kong: Hong Kong SAR Government; 2002.

\section{Tables}


Table 1. Rotated factor analysis of Health Belief Model Scale for oral health behaviors

\begin{tabular}{|c|c|c|c|c|c|c|c|c|c|c|c|}
\hline \multicolumn{2}{|c|}{$\begin{array}{c}\text { Factor } 1 \\
\text { Self-efficacy }\end{array}$} & \multicolumn{2}{|c|}{$\begin{array}{c}\text { Factor 2 } \\
\text { Perceived } \\
\text { benefits }\end{array}$} & \multicolumn{2}{|c|}{$\begin{array}{c}\text { Factor } 3 \\
\text { Perceived } \\
\text { severity }\end{array}$} & \multicolumn{2}{|c|}{$\begin{array}{c}\text { Factor } 4 \\
\text { Perceived } \\
\text { barriers }\end{array}$} & \multicolumn{2}{|c|}{$\begin{array}{c}\text { Factor } 5 \\
\text { Cues to action }\end{array}$} & \multicolumn{2}{|c|}{$\begin{array}{c}\text { Factor } 6 \\
\text { Perceived } \\
\text { susceptibility }\end{array}$} \\
\hline EFF37 & 0.92 & BEN5 & 0.83 & SEV27 & 0.79 & BAR14 & 0.84 & CUE22 & 0.88 & SUS1 & 0.77 \\
\hline EFF38 & 0.90 & BEN6 & 0.81 & SEV26 & 0.77 & BAR13 & 0.82 & CUE21 & 0.86 & SUS2 & 0.75 \\
\hline EFF34 & 0.90 & BEN7 & 0.80 & SEV25 & 0.74 & BAR19 & 0.56 & CUE20 & 0.75 & & \\
\hline EFF39 & 0.88 & BEN3 & 0.78 & SEV30 & 0.71 & BAR15 & 0.55 & CUE23 & 0.43 & & \\
\hline EFF33 & 0.88 & BEN9 & 0.74 & SEV28 & 0.71 & BAR12 & 0.53 & & & & \\
\hline EFF42 & 0.87 & BEN8 & 0.70 & SEV24 & 0.68 & BAR16 & 0.51 & & & & \\
\hline EFF40 & 0.86 & BEN10 & 0.70 & SEV29 & 0.67 & BAR17 & 0.50 & & & & \\
\hline EFF41 & 0.86 & BEN4 & 0.44 & SEV31 & 0.55 & BAR18 & 0.49 & & & & \\
\hline EFF35 & 0.83 & & & SEV32 & 0.55 & BAR11 & 0.32 & & & & \\
\hline EFF36 & 0.82 & & & & & & & & & & \\
\hline \multicolumn{12}{|c|}{ Eigenvalue } \\
\hline 10.41 & & 5.00 & & 3.89 & & 3.08 & & 2.19 & & 1.67 & \\
\hline \multicolumn{12}{|c|}{ Variance explained } \\
\hline 24.79 & & 11.91 & & 9.27 & & 7.33 & & 5.21 & & 3.98 & \\
\hline
\end{tabular}

Table 2. Item-total correlation and internal consistency of Health Belief Model Scale for oral health behaviors

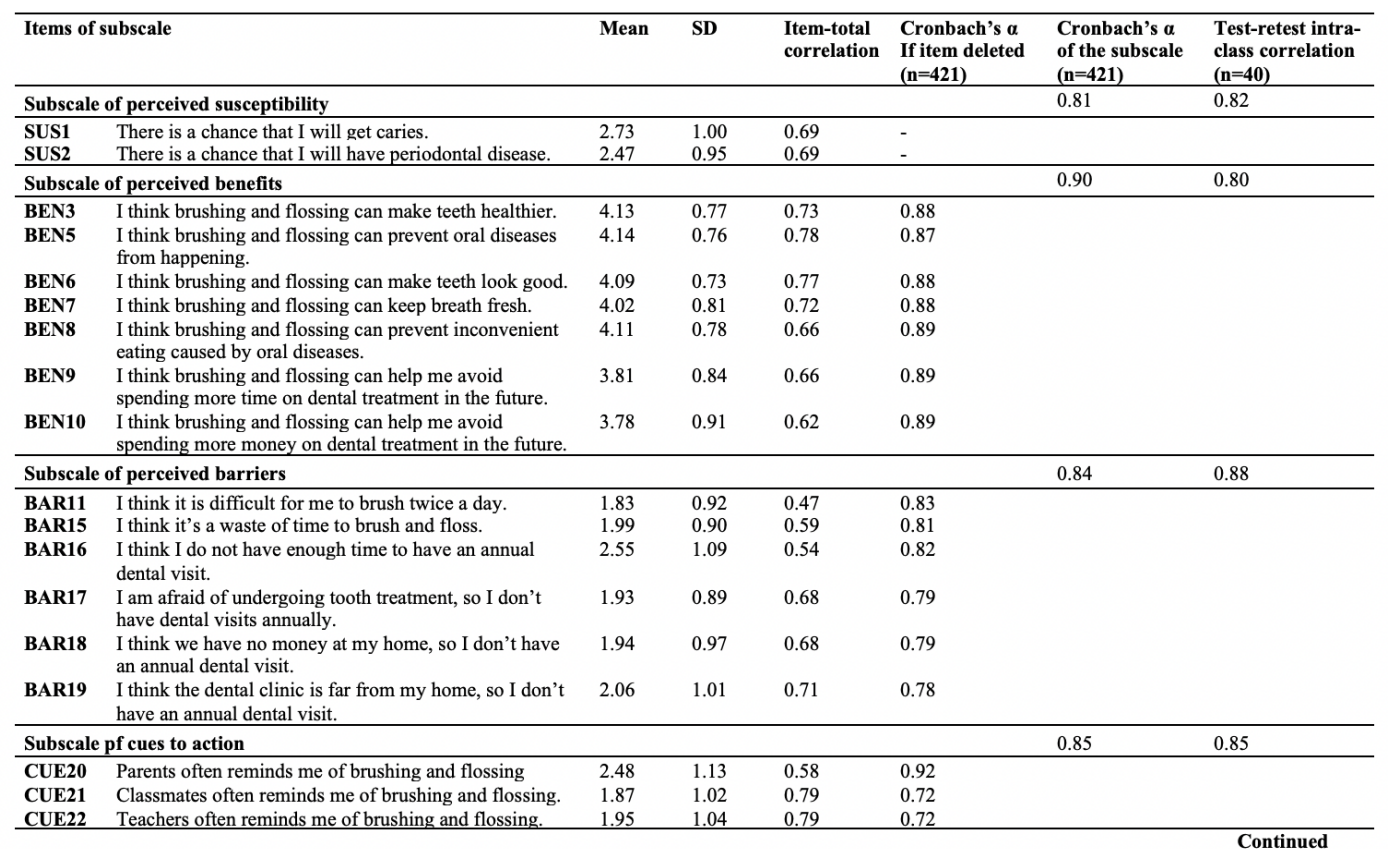




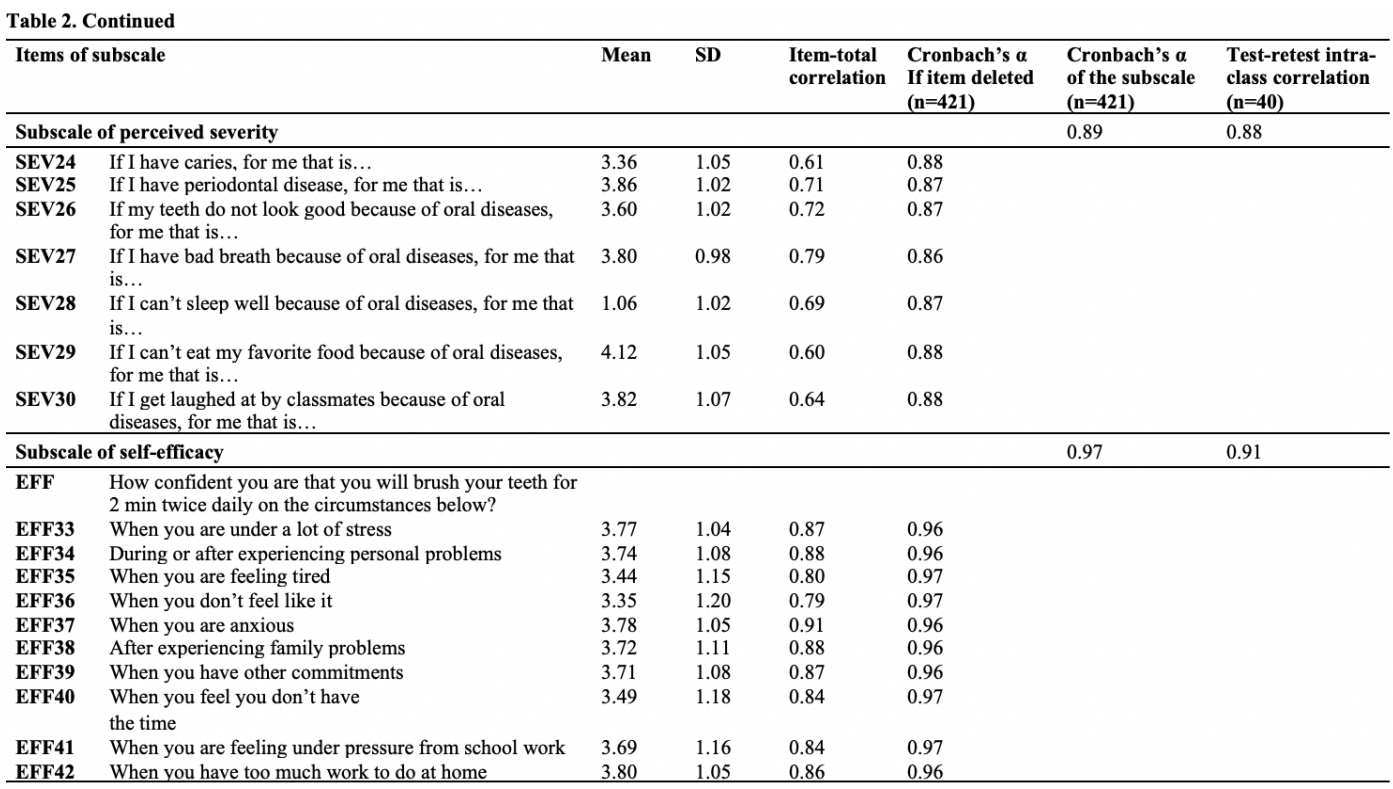

Table 3. HBM factors for predicting favorable oral health behaviors

\begin{tabular}{|c|c|c|c|c|c|}
\hline & B & SE & Wald statistics & OR $(95 \%$ CI $)$ & $\mathbf{P}$ \\
\hline \multicolumn{6}{|c|}{$\begin{array}{l}\text { Predicting brushing twice daily }\left(N=412, \text { Cox \& Snell } R^{2}=0.097 \text {, Nagelkerke } R^{2}=0.160\right) \\
\text { Chi-square }=42.2, d f=6, p<0.001\end{array}$} \\
\hline Perceived susceptibility & -0.16 & 0.17 & 0.91 & $0.85(0.61-1.19)$ & 0.34 \\
\hline Perceived benefits & 0.14 & 0.25 & 0.31 & $1.14(0.71-1.86)$ & 0.58 \\
\hline Perceived barriers & -0.10 & 0.25 & 0.16 & $0.91(0.56-1.47)$ & 0.69 \\
\hline Cues to action & 0.21 & 0.18 & 1.43 & $1.23(0.88-1.74)$ & 1.23 \\
\hline Perceived severity & 0.14 & 0.20 & 0.48 & $1.15(0.78-1.69)$ & 0.49 \\
\hline Self-efficacy & 0.86 & 0.17 & 25.98 & $2.36(1.70-3.28)$ & $<0.001$ \\
\hline \multicolumn{6}{|c|}{$\begin{array}{l}\text { Predicting weekly flossing behavior }\left(N=418, \text { Cox \& Snell } R^{2}=0.069 \text {, Nagelkerke } R^{2}=0.106\right) \\
\text { Chi-square }=30.0, d f=6, p<0.001\end{array}$} \\
\hline Perceived susceptibility & -0.30 & 0.14 & 4.42 & $0.74(0.56-0.98)$ & 0.04 \\
\hline Perceived benefits & -0.01 & 0.22 & 0.001 & $0.99(0.65-1.53)$ & 0.98 \\
\hline Perceived barriers & -0.86 & 0.24 & 12.74 & $0.42(0.26-0.68)$ & $<0.001$ \\
\hline Cues to action & 0.31 & 0.14 & 5.26 & $1.36(1.05-1.77)$ & 0.02 \\
\hline Perceived severity & -0.10 & 0.17 & 0.37 & $0.90(0.65-1.26)$ & 0.54 \\
\hline Self-efficacy & -0.02 & 1.14 & 0.01 & $0.98(0.75-1.29)$ & 0.91 \\
\hline \multicolumn{6}{|c|}{$\begin{array}{l}\text { Predicting regular dental visit }\left(N=419, \text { Cox \& Snell } R^{2}=0.070, \text { Nagelkerke } R^{2}=0.098\right) \\
\text { Chi-square }=30.6, d f=6, p<0.001\end{array}$} \\
\hline Perceived susceptibility & 0.09 & 0.13 & 0.53 & $1.10(0.86-1.41)$ & 0.47 \\
\hline Perceived benefits & -0.21 & 0.19 & 1.15 & $0.81(0.56-1.19)$ & 0.28 \\
\hline Perceived barriers & -1.10 & 0.22 & 26.14 & $0.33(0.22-0.51)$ & $<0.001$ \\
\hline Cues to action & 0.08 & 0.12 & 0.37 & $1.08(0.85-1.37)$ & 0.54 \\
\hline Perceived severity & -0.23 & 0.15 & 2.25 & $0.80(0.59-1.07)$ & 0.13 \\
\hline Self-efficacy & -0.16 & 0.12 & 1.71 & $0.85(0.67-1.08)$ & 0.19 \\
\hline
\end{tabular}

Figures 


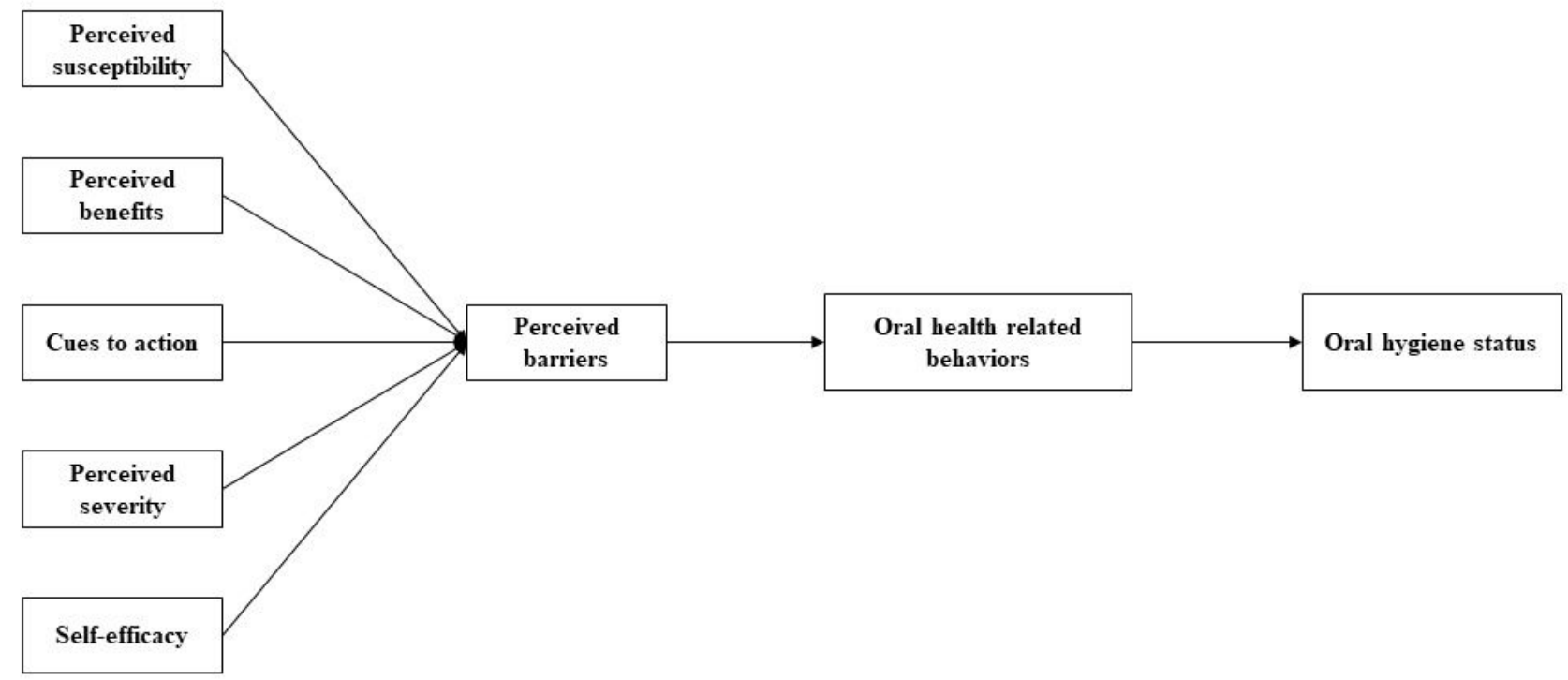

b

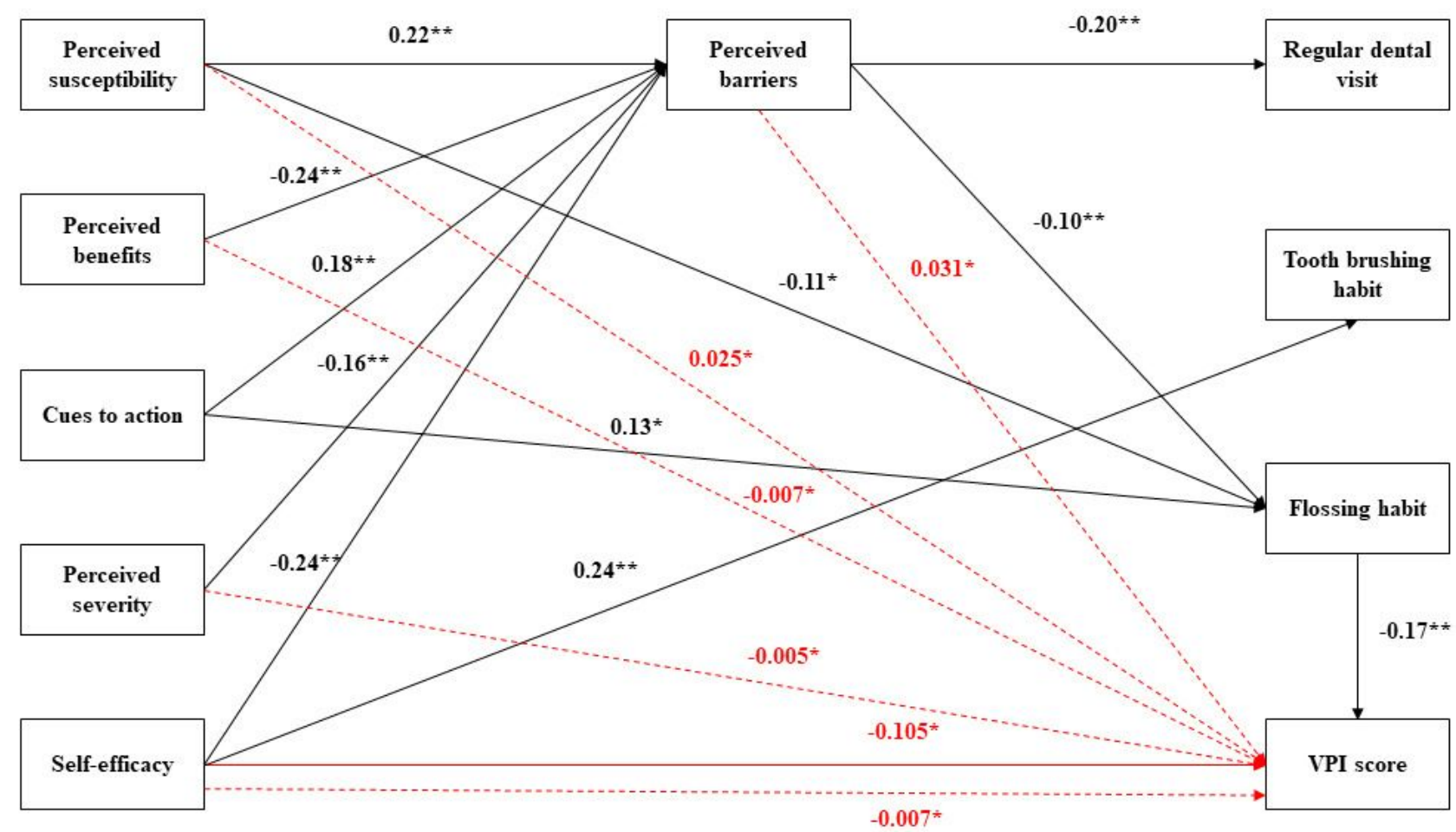

\section{Figure 1}

a. A theoretical model of the impact of HBM on VPI score through oral health behaviors $b$. The final model of path analysis. Standardized direct and indirect effects of HBM variables on VPI score were represented with solid and dotted red lines, respectively $\left({ }^{*} p<0.05,{ }^{*} \mathrm{p} p<0.001\right)$. Error terms and covariance are not presented for ease of understanding. 


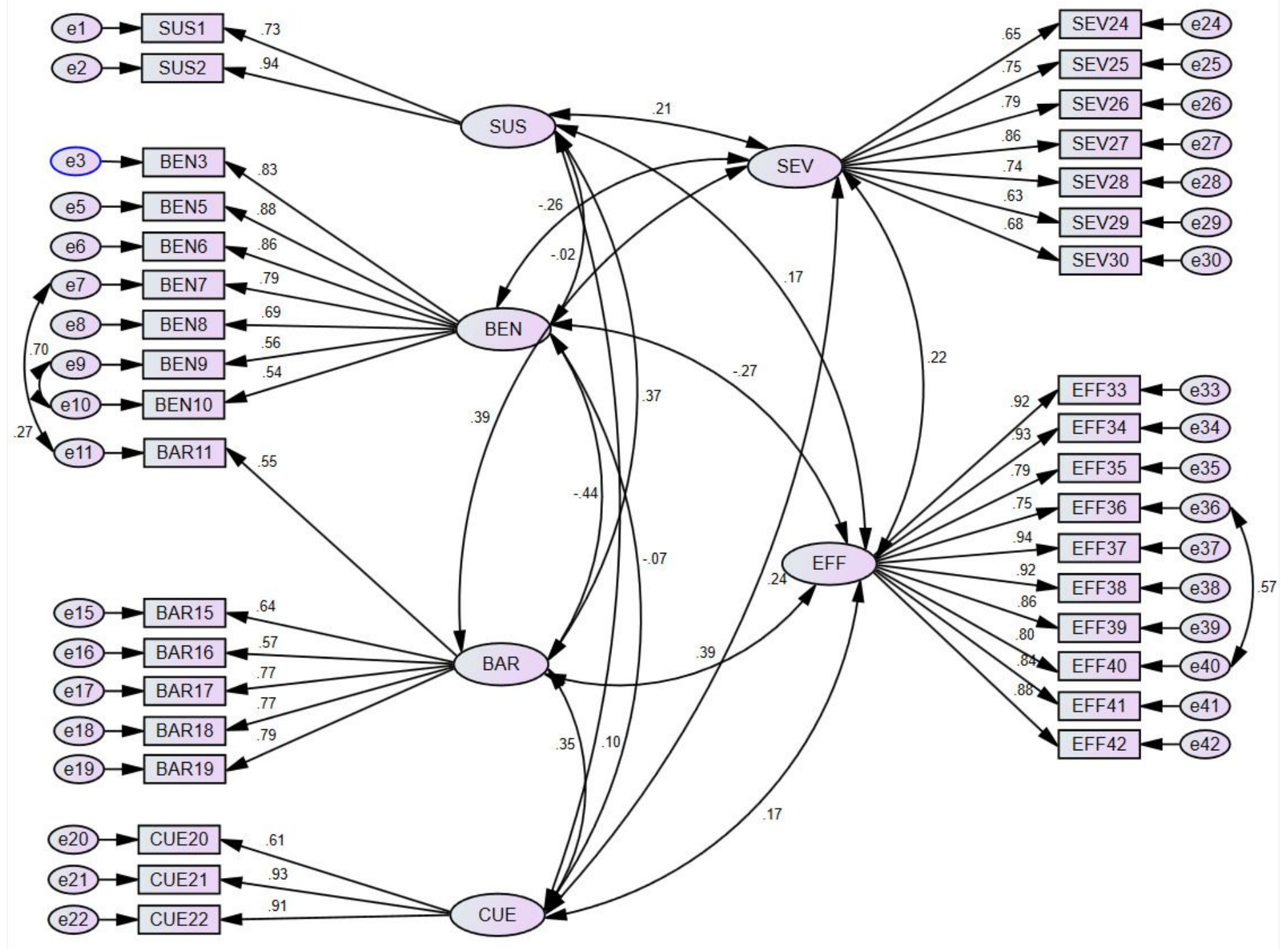

Figure 2

The final version of 35-item OHBQAHBM following CFA of 421 adolescent data fitted the Health Belief Model and its constructs. Standardized coefficients were shown with black lines.

\section{Supplementary Files}

This is a list of supplementary files associated with this preprint. Click to download.

- AppendixTable2.docx

- AppendixTable1..docx 